\title{
SOBRE CONQUISTAS E DESAFIOS: \\ O DIREITO À EDUCAÇÃO QUASE TRÊS DÉCADAS DEPOIS DA CONSTITUIÇÃO FEDERAL
}

\begin{tabular}{c}
\hline CONQUESTS AND CHALLENGES: \\
THE RIGHT TO EDUCATION 30 YEARS AFTER \\
THE FEDERAL CONSTITUTION \\
\hline SOBRE CONQUISTAS Y DESAFÍOS: \\
EL DERECHO A LA EDUCACIÓN CUANDO TRES \\
DÉCADAS DESPUÉS DE LA CONSTITUCIÓN \\
\hline
\end{tabular}

Lucio Jose Dutra Lord 1

RESUMO: Este artigo analisa o direito à educação abordando conquistas e desafios das quase três décadas que transcorreram após a Constituição Federal de 1988. O objetivo é identificar mudanças no significado de direito à educação relacionando-o com políticas públicas conquistadas e com novas demandas que passaram a compor o leque de desafios para o alcance de um direito em construção. A metodologia utilizada neste estudo foi historiográfica com revisão da literatura publicada sobre o tema da educação como direito e como política. As análises mostram grande diferença nas demandas pela educação como um direito em 1990 quando comparadas às décadas seguintes. A ideia de direito à educação incorporou novos sujeitos, novos temas e novos campos de políticas públicas. $\mathrm{O}$ artigo conclui que o direito que envolve a educação ganhou uma grande e complexa dimensão, sendo responsável por conquistas e estabelecendo constantes e novos desafios como condição de seu alcance pleno.

PalavraS-Chave: Educação. Direito. Políticas públicas.

ABSTRACT: This article studies the right to education and shows the achievements and challenges of thirty years after the Federal Constitution of 1988. The text identifies changes in the meaning of right to education and relates to education policies and new demands that have become challenges to the right under construction. The methodology used in this study is historiographical with a review of published literature on education as a right and as a policy. The data show differences in the demands for education as a right in 1990 compared to the following decades. The idea of the right to education has incorporated new actors, new themes and new places of public policies. The article concludes that the right to education has gained a large and complex dimension, making achievements and creating new challenges to be full.

KEYWORDS: Education. Right. Public policy.

RESUMÉN: Este artículo analiza el derecho a la educación abordando conquistas y desafíos de las casi tres décadas que transcurrieron después de la Constitución Federal de 1988. El objetivo es identificar cambios en el significado de derecho a la educación relacionándolo con políticas públicas conquistadas y con nuevas demandas que pasaron a componer la lista de desafíos para el alcance de un derecho en construcción. La

\footnotetext{
${ }^{1}$ Submetido em: 04/09/2017 - Aceito em: 07/02/2018 - Publicado em: 08/02/201.
}

\begin{tabular}{l|c|c|c|c|c|c} 
(C) Rev. Educ. Perspec. & Viçosa, $M G$ & v.8 & n.3 & p.294-308 & set./dez. 2017 & eISSN 2178-8359 \\
\hline
\end{tabular}


metodología utilizada en este estudio fue historiográfica con revisión de la literatura publicada sobre el tema de la educación como derecho y como política. Los datos muestran una gran diferencia en las demandas por la educación como un derecho en 1990 en comparación con las décadas siguientes. La idea de derecho a la educación incorporó nuevos sujetos, nuevos temas y nuevos campos de políticas públicas. El artículo concluye que el derecho a la educación ha ganado una gran y compleja dimensión, teniendo conquistas y estableciendo constantes y nuevos desafíos como condición de su alcance pleno.

PALABRAS ClaVE: Educación. Derecho. Políticas públicas.

\section{INTRODUÇÃO}

Quase três décadas passaram desde a promulgação da Constituição Federal de 1988, chamada também de "constituição cidadã". Nela o tema do direito à educação recebeu atenções especiais e se tornou o mais amplo dos direitos, ocupando hoje parte significativa da máquina estatal e alcançando a população quase que diariamente. Diversas áreas e linhas de pesquisa tomaram a educação como objeto de investigação e chamaram atenção para as conquistas do período e indicam outros desafios a serem resolvidos.

O presente artigo identifica algumas dessas conquistas em termos de direito à educação, relacionando-as com as demandas sociais que repercutiram na resposta estatal em termos de política pública. Ao mesmo tempo, o texto defende que novos desafios surgiram (ou evidenciaram-se) na medida em que foram implantadas políticas educacionais. Isto porque as demandas por educação transformaram os sentidos do direito requerido com o passar das décadas, ampliando ou alterando as reivindicações, o público e os atores envolvidos. Neste sentido, o objetivo do presente artigo é identificar mudanças no significado de direito à educação relacionando-as com políticas públicas conquistadas e com novas demandas que passaram a compor o leque de desafios para o alcance de um direito em construção.

A metodologia utilizada neste estudo foi historiográfica com revisão de literatura publicada sobre o tema no decorrer do período analisado. Os textos referenciais foram organizados e utilizados para descrever um cenário que transcorre das vésperas da promulgação da Constituição Federal de 1988 até chegar nos dias atuais.

\section{CIDADANIA E DIREITO EM 1988}

Apesar de destacado pelas conquistas inscritas no texto da Nova Constituição Federal, o ano de 1988 iniciou marcado pelas desigualdades e violências acumuladas por décadas. Alterar aquela realidade foi o grande desafio colocado para a Constituição (SILVA, 2010). Ou, noutras palavras, deveriam as novas garantias constitucionais fazer frente aos problemas sociais do país. Hoje, três décadas depois, compreender a dimensão do "desafio constitucional" de 1988, em termos de cidadania, exige uma análise do contexto sócio- 
histórico brasileiro e a comparação entre o que vivia a população e o que trouxe o texto constitucional.

O Brasil da década de 1980 já tinha uma população urbana aproximada três vezes maior do que a rural (IBGE, 1990). O país acabara de concluir a sua tardia industrialização com maquinários obsoletos, com energia e matéria prima precárias, com mão de obra sem qualificação, resultando em produtos de baixa qualidade e de alto custo. Mas o governo havia planejado o processo de industrialização desde a década de 1930, e entre 1950 e 1980 o projeto foi implantado com algumas modificações. Para garantir o sucesso duas ações governamentais chamam mais atenção nos estudos sobre o período: uma foi a proteção do mercado interno para que o produto nacional fosse absorvido; outra foi o deslocamento em massa do campesinato para as cidades e zonas de industrialização. Essa segunda ação do governo é a que mais interessa, porque explica boa parte do contexto vivido pela população brasileira em 1988 e que configurou o desafio ao texto constitucional.

O modelo da industrialização tardia brasileira explica o contexto sócio-histórico no qual a Nova Constituição foi inserida. Isto porque o principal efeito sobre a população foi o êxodo rural provocado pelo governo entre as décadas de 1950, 1960 e 1970. O objetivo foi produzir um exército de mão de obra disponível e de reserva, a ponto de que os salários, a baixo da necessidade para a subsistência familiar, se tornassem a única alternativa à população. Isto permitiu que parte do custo da industrialização fosse reduzido e o lucro necessário ao sucesso do processo fosse alcançado por aqueles que nele investiram suas riquezas. Ou seja, o sucesso da industrialização brasileira dependia da viabilidade da acumulação capitalista num país periférico que até então somente estava inserido na globalização pela sua produção agrícola para exportação e pela sua capacidade consumidora dos produtos dos países já industrializados.

Nesta perspectiva não há novidade sobre o maior custo da industrialização ter sido pago pelos corpos dos trabalhadores e trabalhadoras (OMETTO; FURTUOSO; SILVA, 1995). O êxodo rural, necessário ao modelo de industrialização proposto, foi potencializado pelo governo federal mediante uma política de empobrecimento das zonas rurais e carência de serviços públicos. Diante da situação de miserabilidade os mais jovens, homens e mulheres, migraram para as cidades em busca de trabalho assalariado. Na década de 1980, as cidades capitais e cidades médias concentravam desempregados, assalariados desqualificados, analfabetos funcionais, famílias de casais jovens com filhos formadas por aqueles que saíram da agricultura de subsistência.

A baixa escolaridade e os salários dessas famílias reservaram-lhes as periferias urbanas que cresciam diariamente para abrigar novos migrantes, retirantes (VITA, 1989). O crescimento

\begin{tabular}{l|c|c|c|c|c|c} 
() Rev. Educ. Perspec. & Viçosa, $M G$ & v.8 & n.3 & p.294-308 & set./dez. 2017 & eISSN 2178-8359 \\
\hline
\end{tabular}


das favelas acentuava os problemas de falta de água potável e saneamento, habitação irregular, desemprego, vulnerabilidade social, fome e incidia especialmente sobre a infância. Acompanhava esse processo aquilo que alguns convencionaram chamar de "reabertura democrática", o que levou as populações faveladas a organizarem-se para reivindicar ações estatais para a resolução dos seus problemas. A realidade daquele momento, como documentou Durham (1986), forçava os moradores das periferias urbanas a uma experiência comum de carências, onde noções de solidariedade foram se constituindo.

O mesmo período foi marcado pelo surgimento da "nova classe média" brasileira em função da expansão do Estado por meio do crescimento de empresas estatais e órgãos de administração pública (BOSCHI, 1986). Para atender a demanda desse grupo, o governo federal financiou empreendimentos habitacionais nas capitais e cidades médias, e esses foram planejados e executados sobre as áreas de ocupação irregular pelos favelados e pela classe baixa operária resultante do êxodo rural. $\mathrm{Na}$ medida em que os empreendimentos eram iniciados, procedia-se o desalojamento mediante a retirada forçada das famílias operárias com o auxílio das polícias militares. O nível da violência utilizada e o descaso público com aquela população, juntamente com o sentimento de solidariedade entre os excluídos, fez com que as periferias se organizassem politicamente e fizessem frente às opressões.

Houve então um momento propício para que essas organizações populares encontrassem eco dentro da política de novos partidos de esquerda, como no caso do Partido Democrático Trabalhista e do Partido dos Trabalhadores. A ligação entre operariado e partidos com tendência trabalhista seguiu um curso previsível na década de 1980, porque o projeto de reabertura democrática visou englobar as massas populares na política do país mediante procedimentos como a representação definida pelo voto direto. Assim, a emergência do novo modelo de democracia proposto no período dependeu do envolvimento da população. Ou, noutros termos, as massas populares tinham o papel de legitimar a nova democracia (CARDOSO, 1985). Por este motivo, o Estado, nos seus diversos níveis de poder, deixou-se permear pelas demandas populares.

Mas essa permeabilidade não resultou num conjunto de ações que pudessem alterar a realidade dos grupos mais pobres do país - que compunham a maioria da população nacional no período. Havia muitos limites institucionais, escassos recursos econômicos e um histórico de marginalização do operariado no funcionamento do Estado. Havia um modelo econômico claramente falido das décadas anteriores em governos ditatoriais, modelo que comprometeu o país como um todo na década de 1980 e que deixaria profundas marcas na estrutura socioeconômica para as décadas vindouras. Havia um cenário insustentável no início dos anos de 1980. E o novo modelo de democracia, que estava intrínseco ao novo modelo econômico, demandava alterações na ordem legal. Era necessária uma nova constituição e

\begin{tabular}{l|c|c|c|c|c|c} 
(C) Rev. Educ. Perspec. & Viçosa, $M G$ & v.8 & n.3 & p.294-308 & set./dez. 2017 & eISSN 2178-8359 \\
\hline
\end{tabular}


esta deveria selar acordos entre a elite econômica, o aparelho estatal, os novos partidos e as massas populares. Então o desafio constitucional não era atualizar textos legais, mas constituir um modelo de democracia tal como se fazia necessário para ajustar a sociedade brasileira (CARDOSO, 1985).

No novo texto constitucional foi mantido o modelo do sistema tributário de 1967, e ao mesmo tempo, foram inseridas garantias sociais e de participação política inovadoras na história do país. Em síntese, o discurso de cidadania presente na Nova Constituição atendeu às necessidades do novo modelo de política proposto, sem romper com as elites já consolidadas. Os direitos sociais inscritos no texto constitucional e as possibilidades de participação popular em alguns dos espaços institucionalizados da política serviram para legitimar o novo modelo de poder. Mas as classes operárias e seus intelectuais perceberam todo o processo como resultado de uma conquista. Assim, direito e cidadania foram inscritos na Constituição Federal de 1988, contudo seus significados seriam objeto de grandes embates nas décadas seguintes.

\section{A EDUCAÇÃO COMO UM DIREITO EM 1988}

Há vasta literatura sobre as demandas pelo serviço de educação por volta de 1988. Parte dela são estudos sobre os movimentos sociais de periferias urbanas que demandaram creche para as crianças como condição de viabilizar o trabalho de mães operárias. A organização de mulheres mães questionou a atuação dos governos municipais nas políticas educacionais infantis antes mesmo da Constituição Federal de 1988 (LORD, 2011a). Dirigir a demanda para os governos locais foi resultado do amadurecimento político das periferias propiciado, sobretudo, pelo trabalho da Pastoral da Criança e Pastoral Operária, ambas organizações da Igreja Católica dirigidas por grupos de freiras e padres que transitaram entre uma doutrina chamada de libertadora e uma formação crítica marxista. Muito da noção de educação como um direito naquele período resultou das ligações das periferias com outros grupos sociais, transformando as necessidades em projetos políticos que passaram a ser disputados no âmbito dos governos municipais, seja nas secretarias de educação dirigidas pelo poder executivo, seja nas comissões de educação junto ao poder legislativo.

Como mostrou Valla (1988), as demandas por educação às vésperas da Nova Constituição envolviam discursos acerca da libertação das massas trabalhadoras, mediante o acesso ao capital intelectual necessário à mudança social do país. Mas, ao mesmo tempo, as ações governamentais em serviços educacionais se limitavam a pequenas práticas que configurava a redistribuição de uma parte das verbas destinadas a projetos sociais, não configurando uma política educacional. Então, em termos gerais, o acesso do operariado à educação era percebido pelas elites como um modo de assistir aos necessitados. Deslocar o tema da

\begin{tabular}{l|c|c|c|c|c|c|} 
(C) Rev. Educ. Perspec. & Viçosa, $M G$ & v.8 & n.3 & p.294-308 & set./dez. 2017 & eISSN 2178-8359 \\
\hline
\end{tabular}


educação da abordagem assistencialista para uma noção ampla de direito público subjetivo era um desafio a ser vencido pelas organizações sociais no período.

Em nível local, os governos municipais, sentiram antes das elites nacionais a dimensão da demanda operariada pelo serviço educacional. Isto porque o amadurecimento político das periferias ocorreu num cenário de ampliação da representatividade política das massas mediante a eleição para os municípios capitais e as cidades estratégicas. Essas não possuíam eleição e participação política da população durante o regime militar. Então no novo cenário os candidatos aos cargos de vereadores e prefeitos buscaram vínculos com as demandas das periferias urbanas. E, em alguns casos, as periferias produziram seus próprios candidatos e disputaram o eleitorado. Ingressam, desse modo, as demandas das periferias, as demandas dos operariados e, em especial, as demandas das mães operárias de periferias nos espaços institucionalizados de elaboração da política educacional nas municipalidades.

O problema central da educação em 1988 era incluir na prestação aquela parte da população que até então viveu à margem do serviço. Havia o aspecto do cuidado da infância em creches, mas também havia a questão da alfabetização das crianças nas escolas e inclusive a alfabetização dos adultos voltada ao mercado de trabalho. Os três aspectos passaram a compor a agenda de lutas popular, inseridos numa lista de muitas outras demandas que resumiam décadas de exclusão socioeconômica. Assim, a educação discutida a partir das periferias urbanas e dos movimentos sociais em 1988, já englobava outros sentidos que não limitados ao cuidado e alfabetização. Sobressaía o sentido da justiça social e da condição de cidadania. A educação passava a ser interpretada como instrumento de mudança social, sentido esse que parte das periferias urbanas e ingressa nos espaços governamentais e acadêmicos, alcançando legitimidade quando da elaboração do texto constitucional (VALLA, 1988; DUARTE, 2004; LORD, 2011a).

Promulgada a Constituição Federal em 1988, seu texto estabeleceu a educação como um dever do Estado, como um direito de todos e que pode ser demandado em qualquer época da vida. Deste modo, ficou claro que cabe ao poder público ofertar o serviço educacional. Este serviço é universal, aberto a todos e todas que solicitarem caso não ofertado espontaneamente pelo Estado. E o acesso às etapas básicas do serviço educacional é um direito em qualquer época da vida do cidadão, independente da idade ou de outro critério de seleção (DUARTE, 2004).

Mas o texto de lei constitucional não resolveu o problema da educação, nem mesmo garantiu os significados conforme a demanda popular ou viabilizou a instrumentalização do direito. Apesar de estabelecer a competência da oferta dos níveis de educação entre as esferas estaduais e municipais, a Constituição não definiu os aspectos práticos como prazos para a

\begin{tabular}{l|c|c|c|c|c|c} 
() Rev. Educ. Perspec. & Viçosa, $M G$ & v.8 & n.3 & p.294-308 & set./dez. 2017 & eISSN 2178-8359 \\
\hline
\end{tabular}


universalização do serviço. E não havendo prazos, a oferta do serviço, ou acesso ao direito, passou a depender mais uma vez da pressão social sobre os governos.

\section{O DIREITO À EDUCAÇÃO NOS PRIMEIROS ANOS DA NOVA CONSTITUIÇÃO}

Ihering (2006) já chamava a atenção para o fato de que o direito somente se materializa mediante a luta pela sua aplicação prática. E no caso da América Latina O’Donnell (1998) destacava a característica da inefetividade da lei quando essa visa alterar a ordem social já estabelecida. Essas características foram vivenciadas pelo operariado e pelos demais movimentos sociais ligados à educação no período pós-Constituição de 1988.

Os primeiros anos da Nova Constituição foram marcados pela luta da sociedade para efetivar o direito à educação. Especialmente, o ano de 1990, foi marcado pela disputa de projetos em nível das municipalidades. Isto porque foi o período da elaboração das leis orgânicas dos municípios, e os governos municipais estiveram mais próximos das demandas e pressões sociais do que os níveis de governos estaduais e federal. Além disso, o novo desenho institucional trazido pela Constituição Federal colocou os municípios como atores centrais na oferta de diversos serviços públicos, em especial, o de educação.

A grande questão da educação na época era a efetivação da oferta. Ou seja, a educação constava como um direito no texto constitucional federal e estadual, assim como na lei orgânica do município. Mas sua oferta estava limitada e não haviam escolas, salas de aula, vagas e professores para atender todos em idade escolar, nem mesmo aqueles que estavam entre seis e sete anos e que deveriam ingressar no primeiro ano da alfabetização escolar. Entre 1991 e 1992, os pais e mães de crianças em idade escolar, faziam fila nos portões das escolas, dormiam dois ou três dias na calçada para conseguirem matricular os filhos. Deste modo, as demandas sociais estavam focadas na matrícula nas escolas, e o sentido atribuído ao direito à educação versava sobre o ingresso escolar. Este era o principal desafio, e tomou muito das forças de movimentos sociais de periferias, de entidades representativas de professores de escolas públicas, de organizações políticas governamentais e não governamentais.

A carência de políticas públicas em educação e a responsabilidade da oferta pelos municípios geraram um campo propício para experiências teóricas-práticas, de bases ideológicas e das mais diversas origens e fundamentações na educação pública nos primeiros anos da década de 1990. Desde projetos democráticos até outros opressivos foram implantados como condição para que bairros, regiões e grupos sociais tivessem acesso ao serviço educacional. Até mesmo sindicatos de professores tiveram que se submeter a ideologias implantadas nas escolas municipais e estaduais porque as secretarias de educação estavam ocupadas por

\begin{tabular}{l|l|l|l|l|l|l|} 
(c) Rev. Educ. Perspec. & Viçosa, $M G$ & v.8 & n.3 & p.294-308 & set./dez. 2017 & eISSN 2178-8359 \\
\hline
\end{tabular}


pessoas que embebedavam-se em literaturas e viam nas suas gestões a possibilidade de por em prática os modelos. Havia muito tempo do afastamento entre academia e realidade prática, e as primeiras gestões das secretarias de educação dos municípios foram exercidas por pessoas que ingressavam na carreira política e que eram oriundas das universidades. Dotadas de argumentos teóricos, com pouca ou nenhuma crítica epistemológica, gestores da política educacional nos municípios experimentaram suas crenças pedagógicas sobre as periferias urbanas. E neste cenário os primeiros anos da Nova Constituição, "democrática e cidadã”, tiveram pouca democracia e barreiras enormes para a cidadania.

O impacto negativo dessas experiências sobre a educação e sobre as novas gerações de brasileiros somente foi debatido uma década depois quando estudos críticos trataram do histórico da criação de escolas e da expansão da oferta educacional nos municípios (MEDEIROS, 2003; MACHADO, 2004; LORD, 2005). Mostram esses estudos que apesar da lei orgânica do município ter reafirmado valores presentes na Constituição, como a participação democrática na educação, a criação de escolas municipais esteve condicionada ao modelo estabelecido impositivamente pelas secretarias de educação.

Ocorreu que na medida em que as vagas foram sendo ofertadas, as demandas em termos de direito à educação passaram a incorporar a noção de participação democrática. Dentro dessa demanda estavam aspectos relacionados à eleição direta para diretores escolares, a autonomia político-pedagógica da escola, a composição de conselho municipal de educação e a realização de debates públicos tendo como tema a educação ofertada nos municípios. Esses aspectos discutidos pela sociedade ingressaram nos espaços acadêmicos e políticos, repercutindo nos espaços públicos e institucionalizados onde a Nova Lei de Diretrizes e Bases da Educação Nacional (LDBEN) foi debatida em 1995.

\section{O CENÁRIO DA NOVA LEI DE DIRETRIZES E BASES DA EDUCAÇÃO NACIONAL}

Em que pesem as críticas sobre o texto da LDBEN de 1996 ter desconsiderado o trabalho árduo e democrático da sociedade civil que havia produzido outra proposta de legislação, certo é que a lei aprovada buscou resolver vários problemas da política educacional do país identificadas até então. Na Nova LDBEN a noção de direito à educação englobou três aspectos principais: a universalização da oferta do ensino fundamental, a ampliação da oferta do ensino médio e a formação de professores em graduações de licenciaturas. $\mathrm{O}$ desafio era tamanho que a legislação estabeleceu um prazo de dez anos para que critérios como a formação de professores fosse alcançada. Havia uma dura realidade e os idealizadores da legislação percebiam limites financeiros que, sobretudo nos municípios, dificultavam uma política educacional mais ousada (CARVALHO, 1998).

\begin{tabular}{l|c|c|c|c|c|c|} 
(C) Rev. Educ. Perspec. & Viçosa, $M G$ & v.8 & n.3 & p.294-308 & set./dez. 2017 & eISSN 2178-8359 \\
\hline
\end{tabular}


A entrada em vigor da LDBEN seguiu permeada por diversas questões ligadas ao direito à educação. Uma questão central foi a remuneração dos professores e suas condições de trabalho que implicava negativamente sobre o tema da qualidade da educação e que respondia por grandes desigualdades entre regiões do país. Haviam professores leigos atuando nos municípios mais carentes e com remuneração abaixo da metade do salário mínimo pago pelo Instituto Nacional de Seguridade Social (INSS). Ou seja, o trabalho docente em alguns municípios era desqualificado e com remuneração que não garantia a subsistência do professor. Além disso, haviam grandes diferenças entre a formação, remuneração e condições de trabalho entre as redes municipais e estaduais de ensino, entre capitais e cidades do interior, entre regiões de norte a sul.

O governo federal entendeu que em termos de direito à educação deveria priorizar o acesso ao ensino fundamental e redistribuir os recursos financeiros e, para tanto, estabeleceu o Fundo Nacional de Desenvolvimento do Ensino Fundamental (FUNDEF). Estado e municípios recolheriam para o Fundo comum $60 \%$ dos seus recursos legais da educação, e o valor total seria acrescido em $10 \%$ pelo governo federal e depois redistribuído pelo número de alunos atendidos nas redes municipais e estaduais de educação. Em vigor por dez anos, o FUNDEF nunca recebeu incremento do governo federal e acabou por redistribuir os escassos recursos da educação no âmbito da territorialidade dos Estados da Federação. Do montante do FUNDEF 60\% no mínino deveriam ser gastos com os docentes, visando a melhor remuneração e formação dos professores.

Estudos sobre o FUNDEF revelaram outras faces do serviço educacional e que não eram percebidos pelos governos ainda nos primeiros anos de vigor da lei do fundo (VAZQUEZ, 2005). Tratava-se da evasão escolar. Isto porque o FUNDEF iniciou redistribuindo os recursos financeiros por matrículas nas redes de educação municipais e estadual, e observouse grande diferença no número de alunos concluintes ao final do ano letivo. Ficava evidente que havia ampliado o número de matrículas, mas as condições necessárias para a permanência dos estudantes não foram discutidas. Em algumas localidades, as secretarias de educação, levaram servidores para fazerem a matrícula dos alunos nas suas residências, sobretudo, em zonas rurais e muitas vezes, as crianças matriculadas não tinham condições de frequentar as escolas por fatores como a distância entre a casa e a instituição.

Assim, ainda não estava resolvida a questão da universalização das matrículas quando emergiram os problemas da permanência e do sucesso escolar. A nucleação das escolas foi o principal provocador dessa situação. Isto porque os municípios desativaram as escolas rurais multisseriadas para centralizar a oferta em escolas maiores, onde poderiam lotar professores com nível superior, implantar biblioteca, refeitório, quadra de esportes e oferecer todos os anos do ensino fundamental. Essa nucleação distanciou as escolas das residências das

\begin{tabular}{l|c|c|c|c|c|c} 
() Rev. Educ. Perspec. & Viçosa, $M G$ & v.8 & n.3 & p.294-308 & set./dez. 2017 & eISSN 2178-8359 \\
\hline
\end{tabular}


crianças, criou diferenças culturais entre professores e alunos em função das realidades diversas experienciadas (LORD, 2008).

A nucleação das escolas foi um processo que ocorreu em toda a extensão do território nacional. Assim, o novo desafio do poder público foi levar o aluno até a escola, o que destacou as discussões sobre o transporte escolar. Os municípios receberam um repasse do governo federal por aluno transportado, mas esse valor somente cobria o custo daqueles de perímetros urbanos. Os municípios com oferta de transporte em zonas rurais, ou aqueles com perfil de pequenos municípios em termos populacionais, tiveram grandes déficits nas contas da educação anuais em função do transporte escolar (LORD, 2008).

O resultado desse processo de nucleação e urbanização das escolas repercutiu num movimento social que questionou tal política e passou a problematizar inclusive o currículo escolar. De modo geral, esse movimento mostrou que os grupos sociais atendidos pela política educacional pública estavam sendo homogeneizados mediante currículos urbanos em detrimento das realidades rurais e das diferenças culturais nacionais. Havia um conteúdo que em muitos casos oprimia as minorias sociais e ignorava totalmente as realidades vivenciadas pelos alunos. Este movimento crítico alcançou as universidades, seus intelectuais e políticos, e despertou uma noção de direito à educação em que o plural deveria ser contido em projetos político-pedagógicos, em currículos escolares e na formação docente.

O ingresso na década de 2000 foi de intenso debate sobre o reconhecimento de minorias sociais. As discussões internacionais ingressaram no país e deram bases teóricas para a elaboração de políticas educacionais mais amplas, na qual a diferença pudesse ser valorizada. Somava para isso as mudanças no governo nacional e um quadro novo de intelectuais que compuseram o Conselho Nacional de Educação. Eram pessoas com histórico de lutas sociais, oriundas de minorias sociais e que haviam alcançado local de destaque e referência em termos de política educacional. Ao mesmo tempo o Ministério de Educação fez alterações internas no seu organograma e destinou um espaço próprio para a elaboração de políticas educacionais inclusivas.

Também chegava ao Ministério da Educação a demanda social pela ampliação das vagas do ensino superior. Isto porque estados e municípios haviam ampliado significativamente $o$ atendimento educacional, e os egressos do ensino médio começavam a buscar formação posterior. Também parte dessa demanda por ensino superior ocorreu pela redução dos cursos técnicos públicos na gestão do governo federal anterior. Deste modo, o Ministério da Educação precisava responder à demanda e tinha a alternativa de ampliar as vagas das instituições públicas de ensino superior. Contudo isto implicaria no aumento dos gastos em educação do governo federal. Outra alternativa era seguir fomentando a oferta do ensino

\begin{tabular}{l|c|c|c|c|c|c} 
() Rev. Educ. Perspec. & Viçosa, $M G$ & v.8 & n.3 & p.294-308 & set./dez. 2017 & eISSN 2178-8359 \\
\hline
\end{tabular}


superior privado, o que de fato ocorreu mediante a criação do Programa Universidade Para Todos (Prouni). Neste programa o governo abriu mão de receber determinados impostos e as instituições particulares de ensino superior ofertariam algumas vagas de modo gratuito ou parcialmente gratuito aos alunos selecionados pelo governo - critérios como origem socioeconômica e escolar determinaram aqueles que poderiam ingressar no ensino superior pelo programa.

Na década de 2000, a noção de direito à educação, passou a englobar a ideia de diversidade e reconhecimento das minorias sociais e expandiu-se até o ensino superior. Corroborou para isso um contexto de exigência pela LDBEN de que somente poderiam ser professores pessoas com diploma de nível superior (licenciatura plena). Mas o tema do atendimento à infância com a ideia de educação infantil continuou latente no nível local das municipalidades. Tratava-se da noção de educação infantil e não mais do cuidado dos infantes. E mais uma vez as periferias urbanas entram em cena exigindo atendimento à infância, mas dessa vez cobravam que professores das creches fossem formados em pedagogia. $\mathrm{Na}$ prática, o atendimento à infância nas periferias urbanas dos grandes centros, já era realizado por instituições comunitárias e sem fins lucrativos fazia anos. Mas eram professores sem nível superior, e a LDBEN exigia que somente pedagogas e pedagogos atuassem como professores no atendimento infantil. Surge então das periferias os movimentos de educadores populares que demandavam junto aos governos o acesso ao ensino superior. Legitimava suas demandas às exigências da lei, à existência do Prouni e à noção de educação infantil. E em termos políticos, esse período, marcou um amadurecimento político das periferias que conseguiram transformar uma demanda em projeto político. Organizaram-se com outros atores políticos, com universidades e conseguiram ensino superior (MORAES, 2007; LORD, 2011b).

\section{O DIREITO À EDUCAÇÃo PARA ALÉM DA POLÍtiCA: A JUDICIALIZAÇÃO}

O problema da prestação do serviço educacional acompanhou as décadas pós-Constituição de 1988. Ainda na década de 1990, a população mais pobre de São Paulo precisava dirigir-se a vereadores ou outras pessoas com cargos políticos para conseguir matricular os filhos em idade escolar nas escolas. Na década de 2000, a demanda ainda era dirigida a atores políticos, sobretudo, naqueles espaços institucionalizados de políticas educacionais. Mas na década de 2010, a demanda foi judicializada e a busca pelo direito à educação passou a envolver um ator até então com pouco destaque na prestação do serviço educacional, o judiciário.

A judicialização da demanda educacional marcou um novo momento na política educacional no Brasil. Os motivos mais destacados pelos estudos sobre o tema falam da rapidez da resposta e da expansão da atuação do judiciário sobre as políticas sociais de modo geral. Mas o primeiro aspecto que levou à judicialização da prestação educacional foi a inexistência da

\begin{tabular}{l|c|c|c|c|c|c} 
(C) Rev. Educ. Perspec. & Viçosa, $M G$ & v.8 & n.3 & p.294-308 & set./dez. 2017 & eISSN 2178-8359 \\
\hline
\end{tabular}


oferta. Ou seja, as demandas foram judicializadas porque as vagas no serviço educacional não existem. Trata-se do mesmo problema da década de 1980. Observado o período das últimas três décadas, constata-se que o tema do atendimento educacional permaneceu sem resolução. Apesar da ampliação do atendimento e da quase universalização do ensino fundamental, outros níveis da educação não foram resolvidos. Permanece ainda a carência do atendimento da educação infantil, da educação de jovens e adultos e dos alunos com deficiências.

A principal demanda judicializada diz respeito à educação infantil. Este nível do atendimento é demandado desde a década de 1980, especialmente pelas periferias urbanas. Ainda hoje, são as crianças de periferias, de pais operários ou grupos vulneráveis que mais ajuízam pedidos de atendimento em educação infantil. O que difere atualmente é o espaço onde a demanda é buscada. Assim, a atuação do judiciário tem sido no sentido de mandar o poder público fazer o atendimento, de acordo com o que prescreve a lei, estabelecendo para tanto multa diária caso não cumprida a determinação judicial. Deste modo, o trabalho do judiciário tem sido dizer que o direito existe e que ele deve ser cumprido pelo executivo. Ou, noutros termos, o judiciário tem assumido o papel de garantidor da prestação da política pública (TAYLOR, 2007).

A novidade do período atual não é a existência do direito textual, redigido em legislação e estabelecendo quem tem direito e quem deve ofertar o serviço. O direito à educação já estava estabelecido no texto constitucional de 1988. O novo hoje é a existência de um caminho mais rápido para alcance da prestação do serviço e esta novidade corresponde à própria expansão do Estado que tem ampliado a presença e atuação do judiciário em todas as regiões do país.

Os resultados da presença do judiciário nas políticas públicas ainda demandam estudos, mas observa-se até o momento que seu papel é legitimado pela população, e a provocação do judiciário tem sido feita pela parcela mais carente. Contudo, as determinações judiciais ocorrem sempre tendo como referência a pessoa que é sujeita de direitos, e não um grupo populacional. Como as determinações judiciais são para indivíduos, os governos municipais gastam recursos financeiros e humanos para cumpri-las e atendimento pontual a um indivíduo demandante é diferente de política educacional. Notadamente, no caso da educação especial, o atendimento pode envolver um alto custo para o sistema de ensino, inviabilizando ou limitando a elaboração ou implantação de uma política.

O ingresso do judiciário na prestação dos serviços educacionais é peculiar se analisado a partir das secretarias de educação e dos conselhos de educação. Em síntese, a determinação judicial não considera a reserva do possível no caso da educação. Ou seja, o judiciário não considera a capacidade do sistema em atender o demandante, portador ou não de necessidades especiais. Mais ainda, como no caso da data corte estabelecida pelo Ministério

\begin{tabular}{l|c|c|c|c|c|c|} 
(C) Rev. Educ. Perspec. & Viçosa, $M G$ & v.8 & n.3 & p.294-308 & set./dez. 2017 & eISSN 2178-8359 \\
\hline
\end{tabular}


da Educação, o ingresso do judiciário desqualificou anos de estudos sobre a idade escolar e passou a determinar em momentos uma coisa, em momentos outra. Uma análise mais profunda sobre esse tema é necessária, sobretudo para que o desenho institucional da elaboração das políticas educacionais seja refeito e englobe, desde o início, o judiciário como ator político e qualifique as decisões com entendimentos coerentes não somente sobre o texto da lei, mas das demais normatizações que têm como origem espaços democráticos de participação social.

\section{CONCLUSÃO}

A observação das demandas educacionais desde as vésperas da Constituição Federal de 1988 até os dias atuais mostra transformações profundas de sentidos tanto em termos cronológicos como dentre os grupos sociais envolvidos. A educação constituiu-se campo de embate de projetos políticos e, em algumas experiências, o exercício do poder ao impor uma determinada ideologia pedagógica se deu em detrimento do processo democrático.

Este estudo mostrou que o tema do direito à educação tem composto a agenda de lutas dos movimentos sociais ao longo das últimas três décadas, alterando seu sentido na medida em que conquistas são obtidas em termos de políticas públicas educacionais. Ao mesmo tempo, essas conquistas abrem novas perspectivas e a noção do que cabe como direito em termos de educação, amplia-se e engloba novas demandas que se tornam desafios. Em alguns casos, como na nucleação escolar, a implantação de uma política educacional acaba por provocar novas demandas, incluindo temas anteriormente não discutidos como o transporte escolar e as diferenças culturais entre os sujeitos do processo educacional.

Há uma dinâmica observável no direito à educação que está relacionada ao ingresso de novos atores políticos na cena. É verdade que o contexto socioeconômico vivido pelo Brasil nas últimas três décadas influenciou o conceito de direito e de educação, mas há um peso expressivo dos atores políticos, personagens que noutros tempos da história haviam sido silenciados. E o essencial do direito à educação é esta apropriação que os sujeitos fazem, transformando-o.

\section{REFERÊNCIAS}

BOSCHI, Renato. A abertura e a nova classe média na política brasileira: 1977 - 1982.

Revista Dados, Rio de Janeiro, v. 29, n. 1, p. 5-24, 1986.

CARDOSO, Fernando Henrique. A democracia necessária. São Paulo: Papirus, 1985.

\begin{tabular}{l|c|c|c|c|c|c|} 
(C) Rev. Educ. Perspec. & Viçosa, $M G$ & v.8 & n.3 & p.294-308 & set./dez. 2017 & eISSN 2178-8359 \\
\hline
\end{tabular}


CARVALHO, Djalma Pacheco de. A Nova Lei de Diretrizes e Bases e a formação de professores para a educação básica. Revista Ciência e Educação, v. 5, n. 2, p. 81-90, 1998.

DUARTE, Clarice Seixas. Direito público subjetivo e políticas educacionais. Revista São Paulo em Perspectiva. São Paulo, v. 18, n. 2, p. 113-118, 2004.

DURHAM, Eunice. A cidade vista da periferia. Revista Brasileira de Ciências Sociais. Rio de Janeiro. v. 1, n. 1, p. 84-99, 1986.

FEDOZZI, Luciano. O poder da aldeia: gênese e história do orçamento participativo em Porto Alegre. Porto Alegre: Tomo Editorial, 2000.

IBGE, Instituto Brasileiro de Geografia e Estatística. Censo demográfico de 1980 e 1990. Rio de Janeiro; IBGE, 1990.

IHERING, Rudolf Von. A luta pelo direito. São Paulo: Martin Claret, 2006.

LORD, Lucio. O Conselho Municipal de Educação de Porto Alegre: estrutura, financiamento e papel político-pedagógico. (Dissertação de Mestrado). Porto Alegre: PPGEDU/UFRGS, 2005

LORD, Lucio. Financiamento do transporte escolar e a questão das zonas rurais no Brasil. Revista da Faculdade de Educação. Cáceres, ano VI, n.9, p. 129-140, jan/jun. 2008.

LORD, Lucio. Educação, política e periferia: estudo sobre o movimento de educadores populares em Porto Alegre. (Tese de Doutorado). Campinas, IFCH/UNICAMP, 2011a.

LORD, Lucio. Novas experiências no ensino superior: o caso da PUCRS e a criação do curso de pedagogia para educadores populares. Revista Brasileira de Política e Administração da Educação. v. 27, n. 3, p. 361-588, set/dez. 2011b.

MACHADO, Carlos Roberto da Silva. A gestão democrática do/no sistema educacional e a democracia sem fim. In: Ensino médio: ciência, cultura e trabalho. Brasília: MEC, 2004.

MEDEIROS, Isabel Letícia Medeiros de. Gestão democrática na rede municipal de educação de Porto Alegre de 1989 a 2000: a tensão entre reforma e mudança. (Dissertação de Mestrado). Porto Alegre: PPGEDU/UFRGS, 2003.

MORAES, Salete Campos de, e outros. A educação de jovens e adultos na FACED/PUCRS: reconfigurando saberes. Revista de Educação da PUCRS. Porto Alegre, ano XXX, n. Especial, p. 77-86, out. 2007.

O’DONNELL, Guillermo. Poliarquias e a (in)efetividade da lei na América Latina. Revista Novos Estudos Cebrap, São Paulo, n. 51, p. 37-61, 1998.

\begin{tabular}{l|c|c|c|c|c|c} 
(C) Rev. Educ. Perspec. & Viçosa, $M G$ & v.8 & n.3 & p.294-308 & set./dez. 2017 & eISSN 2178-8359 \\
\hline
\end{tabular}


OMETTO, Ana Maria Holland; FURTUOSO, Maria Cristina Ortiz; SILVA, Marina Vieira da. Economia brasileira na década de oitenta e seus reflexos nas condições de vida da população. Revista Saúde Pública, v. 29, n. 5, p. 403-414, 1995.

SILVA, José Afonso da.Curso de Direito Constitucional Positivo. São Paulo: Malheiros, 2010.

TAYLOR, Matthew. O judiciário e as políticas públicas no Brasil. Dados - Revista de Ciências Sociais. Rio de Janeiro, v. 50, n. 2, p. 229-257, 2007.

VALLA, Victor Vincent. Educação popular: libertação das classes populares ou socialização da verba pública? Revista Educação e Sociedade. Campinas, Ano X, n. 29, p. 73-84, 1988.

VAZQUEZ, Daniel Arias. Desequilíbrios regionais no financiamento da educação: a política nacional de equidade do FUNDEF. Revista de Sociologia e Política, Curitiba, n. 24, p. 149$164,2005$.

VITA, Álvaro de. Sociologia da sociedade brasileira. São Paulo: Ática, 1989.

\section{Sobre a autora}

1Lucio Jose Dutra Lord - Sociólogo e Advogado, Mestre em Educação e Doutor em Ciências Sociais. Professor Adjunto de Sociologia na Universidade do Estado do Mato Grosso. E-mail: luciolord@hotmail.com - ORCID: http://orcid.org/0000-0002-7552-3637 